\title{
La vocal /a/ àtona final al Pallars Sobirà i la vall Fosca ${ }^{1}$
}

\author{
IsAAC BEÀ \\ Universitat de Lleida \\ ibepons@gmail.com \\ Recibido: mayo de 2013. Aceptado: junio de 2013
}

\begin{abstract}
Resum: Aquest article és el resultat de l'anàlisi espectrogràfica de la vocal /a/ àtona en posició final absoluta al Pallars Sobirà i a la Vall Fosca. Es comparen els resultats amb els de les vocals tòniques del lleidatà i la neutra del català central, s'analitza l'efecte de la coarticulació en aquests resultats i es comprova si existeix algun tipus de variació geogràfica freqüencial en el territori analitzat.
\end{abstract}

Paraules clau: Fonètica, pallarès, anàlisi espectrogràfica.

\begin{abstract}
This article presents the results of the spectrographic analysis of non-stressed vowel /a/ in absolute final position in Pallars Sobirà and la Vall Fosca. These results are compared with those obtained from analyses of the tonic vowels of lleidatà and the schwa of central Catalan. The effect of co-articulation in these results is also analysed. Lastly, the existence of transitions in terms of geographical variation in the analysed territory is sought for.
\end{abstract}

Key Words: Phonetics, pallarès, spectrographic analaysis.

\section{INTRODUCCIÓ}

Dins del marc de l'estudi dels dialectes catalans del Pirineu que duu a terme l'OLLPP' ${ }^{2}$, dirigida per Ramon Sistac, ens hem adonat que la pronúncia de la

1 Agraïm al Ministerio de Educación y Ciencia el suport econòmic que hem rebut en la concessió del projecte FFI2011-28091 i sense el qual aquest article no hauria sigut possible.

Així mateix, destaquem que aquest article forma part d'un estudi d'abast més gran que pretén analitzar la parla del Pallars Sobirà i la Vall Fosca mitjançant la metodologia emprada per Sistac (1993) a l'Alta Llitera, Navarro (1996) a la Terra Alta, Segura (2001) al Baix Vinalopó o Cubells (2005) a la Ribera d'Ebre. Concretament, aquest article n'és una part del vocalisme àton.

2 OLLPP, Oficina de Llengua i Literatura de Ponent i del Pirineu, grup de recerca consolidat de la Generalitat de Catalunya. 
vocal /a/ en posició final àtona es percep molt posterior en moltes de les entrevistes que tenim enregistrades. És un fenomen força comú, però no generalitzat, en els parlants del Pallars Sobirà i la Vall Fosca. De fet, aquest tancament arriba fins al punt que, a vegades, el so es distingeix directament com una $o$, ja sigui oberta o tancada. El mateix Alcover (2006: 128-129) deixava constància d'aquesta pronúncia especialment tancada en el seu dietari de l'excursió filològica de 1906 fent referència al dialecte d'Isil i d'Isavarre:

Hi trobam particularitats fonètiques i morfològiques molt curioses. Hi trobam la $e$ àtona tan tancada (e) que arriba a $i$ (llibri, pari, mari). La $a$ àtona final sona en les formes verbals i en molts de noms casi com $o$ tancada (o) o castellana $($ mirabo $=$ mirava $;$ mirario $=$ mireria $;$ Ke is miréso $=$ miràs; tenibo $=$ teniba $=$ tenia $)$.

També al seu diccionari (DCVB) trobem referències a aquesta /a/ final velaritzada, com per exemple a l'entrada de taronja, on documenta una pronúncia amb [o] (torónzo) a la Torre de Cabdella, una pronúncia que en el nostre cas hem testimoniat sempre amb [a]; i Coromines (1976: 35) parlava d'una «- $a$ posttònica final» que «es pronuncia quasi sempre com una $a$ relaxada». Però si volem afinar més aquesta percepció, no ens podem quedar amb la intuïció: és necessària una anàlisi acústica d'aquestes vocals per situar-les exactament dins del trapezi vocàlic.

El català nord-occidental és un dialecte poc estudiat fonèticament mitjançant l'anàlisi espectrogràfic. Alamon (1984: 79-88) va analitzar els vocoids lleidatans amb una aproximació espectrogràfica de les 7 vocals en posició tònica i en un context oclusiu, amb el resultat d'una lleu desviació típica respecte a d'altres estudis anteriors del català central que ell va atribuir a la variació dialectal. Posteriorment, Carrera (2001) va analitzar les vocals [e] i [a] àtones del nord-occidental en posició pretònica inicial absoluta; més endavant, la mateixa Carrera (2002: 149-167) va caracteritzar acústicament les vocals àtones emeses a la televisió de Lleida d'alguns morfemes de la 3a. persona del singular, de la vocal final de noms, de la preposició de seguida de l'article el i de la vocal de l'article $e l$, per detectar si existeix la vocal neutra en català nord-occidental. Finalment, també destaquem la monografia de Julià, Romero i Creus (2004), una síntesi descriptiva del dialecte nord-occidental amb les seues subvarietats seguida d'una sèrie d'orientacions de tipus ortoèpic adreçades a l'ús formal.

Precisament en aquests estudis que acabem d'esmentar, Carrera analitzà el paper fonamental que exerceix la coarticulació en la variabilitat de les solucions fòniques d'aquestes vocals i va arribar a la conclusió que aquesta variabilitat no podia ser atribuïda a l'al·lofonia.

En el nostre cas, ja que no hem trobat cap estudi d'aquest tipus centrat en la zona del Pirineu, pretenem:

a) Analitzar una mostra significativa vocals /a/ en posició final del Pallars Sobirà i la Vall Fosca i situar-les dins del trapezi acústic. Escollim les vocals en posició final perquè són les que es perceben més velaritzades. 
b) Comprovar l'efecte de la coarticulació en aquest procés.

c) Examinar si existeix variació diatòpica regular en la realització d'aquestes vocals i concloure si el fenomen és degut o no a un procés de canvi.

\section{METODOLOGIA}

El corpus amb el qual hem elaborat aquest article prové del projecte Aixal$d a$. Es tracta d'un projecte engegat per la mateixa OLLPP i Ramon Sistac amb l'objectiu de recollir, sistematitzar i classificar tota una sèrie d'entrevistes realitzades al Pallars Sobirà i a la Vall Fosca amb intenció d'estudiar-les posteriorment des de la major quantitat de vessants possibles. El projecte ha aconseguit realitzar fins avui un total de 251 entrevistes en 108 poblacions diferents.

Per realitzar les entrevistes, l'OLLPP va decidir utilitzar una metodologia que intentés evitar al màxim la paradoxa de l'observador de què parlava Labov i segons la qual els informants centren l'atenció en el tipus de discurs que emeten quan es troben sota la pressió de saber que la conversa que efectuen queda enregistrada.

Per aconseguir-ho, les enquestes van ser dutes a terme per entrevistadors residents a la mateixa zona i, sempre que fou possible, es va intentar que l'informant conegués prèviament l'entrevistador. D'aquesta manera ja s'havia establert una relació de confiança precedent que permetia un nivell de conversa més espontani i informal. Una altra particularitat de les entrevistes era que l'entrevistador no n'explicava el motiu real fins al final, si és que l'acabava explicant. En aquests casos, l'informant donava per fet que l'entrevista responia a motius històrics, sobretot en relació amb la Guerra Civil o a la vida al camp, ja que les preguntes dels entrevistadors, prèviament formats per l'OLLPP, anaven encaminades a buscar «història de vida», per contribuir a evitar la paradoxa de l'observador de la qual parlàvem abans: Quina era la rutina del dia a dia al camp? Quin era tot el procés que se seguia a la matança del porc?

Pel que fa a la tipologia dels informants, és necessari fer un cop d'ull a la particularitat de la zona que estudiem i al procés de desaparició que pateix el dialecte. Aquest procés de desaparició, irreversible segons Pep Coll, té diverses causes, però la que més va afectar a la consecució del projecte fou una en concret: el despoblament. En paraules del mateix Coll (1991: 97):

En més d'un poblet, l'obertura de la carretera ha precedit la diàspora dels seus habitants. La nova pista només els ha servit perquè s'acabessin de decidir i poguessin abandonar més de pressa la casa i l'argenda. [...] Al llarg dels darrers cent anys, el Pallars Sobirà ha perdut tres quartes parts de la població, mentre que els habitants del Jussà s'han vist reduïts a la meitat.

Certament, és molt comú sentir a les entrevistes que la construcció de les carreteres, un fet molt esperat per tothom, va servir perquè els habitants abandonessin la zona. A la vegada, el Pallars ha vist com a partir dels anys 80 es tornava a repoblar sobretot amb gent no nascuda a la zona: els neorurals, molts 
dels quals provenien d'àrees de parla oriental, de manera que avui en dia no és estrany sentir vocals neutres pels carrers de Llessui, per exemple. Aquest fet comportà un problema a l'hora de decidir quins havien de ser els informants que havíem d'escollir per realitzar el projecte. D'una banda, si s'estenia el ventall a tota la població els resultats haurien donat parlars molt diversos segons la procedència dels informants. Si només s'haguessin escollit els nascuts al Pallars, hi hauria hagut el mateix problema amb els informants més joves residents amb famílies de parla oriental, de manera que al final la tipologia de l'informant va acabar coincidint força amb el que Chambers i Trudgill (1980: 56-59) van anomenar la població NORM (non-mobile older rural males): homes vells, rurals i sedentaris. La majoria dels enquestats foren homes i dones d'edat avançada que havien viscut pràcticament tota la vida al Pallars.

A partir de les entrevistes obtingudes amb el projecte Aixalda, hem seguit el següent procediment:

1. Escollir diversos fragments on la vocal /a/ es pronunciava en posició final absoluta; és a dir, amb una pausa posterior de manera que per comprovar l'efecte de la coarticulació només ha calgut tenir en compte la consonant anterior.

2. Analitzar acústicament els segments escollits de les entrevistes amb el programa Praat ${ }^{3}$.

3. Aplegar els resultats segons les freqüències del primer i el segon formant i segons el context contigu a la vocal.

4. Realitzar una anàlisi descriptiva situant les vocals dins del trapezi acústic i comprovant l'efecte de la coarticulació.

5. Plasmar els resultats dins d'un mapa per comprovar la variació diatòpica de les vocals.

\section{RESULTATS}

A l'hora de seleccionar els diferents fragments de les entrevistes que ens podien ser vàlids ho hem fet tenint en compte els següents contextos adjacents que hem extret de Recasens (1986): consonants labials, consonants dentoalveolars, consonants palatals, consonants velars $i$ consonant lateral alveolar velaritzada.

3 He d'agrair al Laboratori de Fonètica Aplicada «Pere Barnils» i en especial a Ruben Manuel les explicacions respecte al funcionament del programa i a la doctora Imma Creus els consells respecte al procediment de les anàlisis. A ella i al doctor Joan Julià-Muné els agraeixo també la correcció final que han fet de l'article. El programa Praat, creat pels professors Paul Boersma i David Weenink de la Universitat d'Amsterdam es pot descarregar del següent web: http://www. fon.hum.uva.nl/praat/ [consulta: 7 de gener de 2013]. 
Els resultats de les freqüències formàntiques són els següents:

(consulteu les Taules 1, 2, 3, 4 i 5)

Els següents gràfics mostren la dispersió de les freqüències segons cada context. Com a model de mostra $\mathrm{i}$ per tenir punts de referència, hi hem inclòs les frequiències formàntiques de les 7 vocals tòniques del lleidatà extretes d'Alamon (1984: 84) i la de la vocal neutra del català oriental central en un context simètric CVC, extreta de Recasens (1986: 131).

(consulteu la Taula 6)

(consulteu els gràfics 1, 2, 3, 4 i 5)

Pel que fa als mapes, hem marcat amb un símbol diferent els intervals de frequiències de $100 \mathrm{~Hz}$ per a la F1 i de 200 per a la F2. La distribució que hem obtingut és la següent:

(consulteu els mapes 1, 2, 3, 4, 5, 6, 7, 8, 9 i 10)

\section{DISCUSSIÓ}

Tal com podem veure als gràfics, el primer que crida l'atenció és la gran dispersió que assoleix la vocal /a/ independentment del punt d'articulació de la consonant adjacent. Trobem des de realitzacions més anteriors a la [e] fins a més posteriors a la [u] pel que fa a la F2, mentre que per a la F1 trobem des de vocals més obertes que la [a] fins a més tancades que la [e], algunes de les quals han arribat gairebé a la mateixa frequiència que la [u] del lleidatà. Aquest fet dóna una idea de la capacitat perceptiva d'interpretació del cervell humà, el qual identifica com la mateixa vocal una quantitat elevadíssima de realitzacions que es mouen per tots els punts que hem especificat.

Queda justificada, per tant, la hipòtesi que teníem a l'inici d'aquest treball: al Pallars Sobirà i la Vall Fosca, algunes de les vocals /a/ en posició final es realitzen com a oo (sobretot obertes, però també alguna de tancada) o en posicions molt pròximes.

D’altra banda, també cal tenir en compte el paper de la coarticulació en tot aquest procés. En els casos que era d'esperar (en contacte amb consonants labials i en contacte amb la consonant lateral alveolar velaritzada), podem veure com un gran nombre de pronúncies se situen en una zona molt pròxima a la [o], però també en la resta de casos es pot veure que la majoria de les pronúncies que hem analitzat tenen una F2 per sota de la [a] del lleidatà.

Treballs anteriors, com ara els de Recasens (1986) i Carrera (2001a) ja havien analitzat aquest efecte. Recasens havia estudiat el context CVC i el context sVk, i Carrera els contextos \#VC, C $+e l$ (article), de (prep) $+e l / l a, \mathrm{CV}+\mathrm{C}^{4}$ i CV\#

4 Vocal de verbs i de noms en posició final no absoluta. 
final absoluta. Els nostres resultats, tot i que els contextos, exceptuant una part del treball de Carrera, no eren exactament els mateixos, no difereixen gaire dels seus:

\section{Consonants labials $+/ \mathbf{a} /$}

El punt d'articulació amb els llavis tancats fa que les vocals que estan en contacte amb aquestes consonants tinguin certa tendència a orientar-se cap a la part posterior del trapezi vocàlic. En el nostre cas trobem una majoria de pronúncies amb la F2 per sota de la [ə] i pròximes a la [0].

\section{Consonants dentoalveolars $+/ \mathrm{a} /$}

Aquest tipus de consonants són les que menys intervenen en la pronúncia de la vocal següent i per tant, les que s'han localitzat més a la part central del trapezi. Tanmateix, la majoria de les pronúncies es troben amb una F2 per sota de la [a] del lleidatà analitzada per Alamon, la qual cosa ens indica que la /a/ final del Pallars Sobirà i la Vall Fosca es pronuncia més tancada de manera natural.

Cal notar, també, el fet que en contacte amb les dentoalveolars, algunes de les realitzacions de la vocal que hem analitzat es presenten en una zona molt pròxima a la vocal neutra.

\section{Consonants palatals $+/ \mathbf{a} /$}

El contacte amb consonants palatals augmenta F2 i situa la majoria de pronúncies entre la $[a]$ i la $[\varepsilon]$ amb una variació considerable de la F1. És l'únic dels contextos que situa un major nombre de pronúncies amb una F2 per sobre de la [a] del lleidatà. Els resultats de Recasens i Carrera per a les coarticulacions on intervenien consonants palatals també indicaven un augment de la F2.

\section{Consonants velars $+/ \mathbf{a} /$}

En contacte amb les consonants velars, la /a/ final es mostra força centralitzada amb algunes excepcions on la $\mathrm{F} 2$ perd frequiència. Com que les consonants velars, a priori, no interfereixen excessivament en la vocal següent, cal pensar que aquest fet (la velarització de la /a/ en posició final) es tracta d'una característica pròpia del dialecte.

\section{Lateral alveolar velaritzada $+/ \mathbf{a} /$}

La consonant lateral alveolar velaritzada és la que en el nostre cas ha presentat una tendència major cap al tancament de la vocal. Dels 20 casos analit- 
zats només 3 han mostrat una F2 per sobre de la [a] del lleidatà. El contacte amb la [1] és (entre tots els que hem analitzat) el que més influeix a l'hora de percebre el tancament de les /a/ finals.

\section{CONCLUSIONS}

Podem concloure, basant-nos amb tots els resultats obtinguts, que la tendència natural del dialecte de la zona que hem estudiat és la de velaritzar les /a/ en posició final.

Pel que fa als mapes, podem veure que la distribució dels formants per la zona estudiada no segueix un patró establert i presenta una concreció força atzarosa. En tots els mapes, tant per a la F1 com per a la F2 trobem els diferents intervals de freqüències repartits per arreu.

Per tant, afirmem que si la variació formàntica al Pallars Sobirà i la Vall Fosca segueix alguna pauta, aquesta no és diatòpica i per tant, no és el resultat d'un procés de canvi.

\section{BIBLIOGRAFIA}

DCVB = Diccionari català-valencià-balear.

Alamon, F.: (1984) «Espectrografia de vocoids lleidatans», dins JULIÀ, Joan (ed.) Folia Phonetica: revista del Laboratori de Fonètica «Pere Barnils». Lleida: Estudi General de Lleida, Universitat de Barcelona, pp. 79-88.

Alcover, A.M. - Moll, F. de B. (1930-1968) Diccionari Català-Valencià-Balear, 10 volums. Palma de Mallorca: Editorial Moll. [Disponible a: http://dcvb. iecat.net Consulta 15 de gener de 2013]

Alcover, A.M. (2006) Dietari de l'excursió filològica 1906. Edició a cura de Pilar Perea. Sabadell: Proa.

Carrera, J. (2001a) «Algunes consideracions generals sobre l'anàlisi acústica de [e] i [a] àtones», dins Estudios de Fonética Experimental XI, pp. 67-87. [Disponible a http://stel.ub.edu/labfon/sites/default/files/2001-1.pdf Consulta 2 de gener de 2013]

Carrera, J. (2001b) «La normativització del català modifica els hàbits fonètics dels parlants?» dins Llengua \& Literatura 12, p 175-199. [Disponible a http://revistes.iec.cat/index.php/LLiL/article/view/18234.001/44554 Consulta 4 de gner de 2013]

Carrera, J. (2002) «Existeix la vocal neutra en català nord-occidental? Caracterització acústica d'algunes vocals àtones emeses a la televisió de Lleida». dins Zeitschrift für Katalanistik 15, pp. 149-167. [Disponible a http://latina. phil2.uni-freiburg.de/pusch/zfk/15/carrera_sabate.pdf Consulta 2 de gener de 2013] 
Chambers, J.K. - Trudgill, P. (1980) Dialectology. Cambridge: C.U.P. Traducció espanyola: La Dialectología. Madrid: Visor Libros 1994. [Cito per aquesta edició.]

Coll, P. (1991) El parlar del Pallars. Barcelona: Empúries.

Coromines, J. (1976) «El parlar de Cardós i Vall Ferrera» A: Entre dos llenguatges. Barcelona: Curial Edicions Catalanes, pàg 29-65.

Cubells, O. (2005) Els parlars de la Ribera d'Ebre. Estudi geolingüístic. Tarragona: Universitat Rovira i Virgili (Departament de Filologia Catalana) [Tesi doctoral. Disponible a http://www.tdx.cat/bitstream/handle/10803/8776/ Tesi.pdf?sequence $=1$ Consulta: 7 de gener de 2013]

Julià, J; Romero, Sílvia; Creus, Imma (2004) El català nord-occidental. Descripció i orientacions ortoèpiques. Lleida: Pagès editors.

Julià, J. (2005) Fonètica aplicada catalana. Barcelona: Ariel.

Navarro, P. (1996) Els parlars de la Terra Alta. Estudi geolingüístic. Tarragona: Universitat Rovira i Virgili (Departament de Filologia Catalana). [Tesi doctoral. Disponible a http://www.tdx.cat/bitstream/handle/10803/8970/ Navarro.pdf?sequence $=1$ Consulta: 7 de gener de 2013]

Recasens, D. (1986) Estudis de fonètica experimental del català oriental central. Barcelona: Publicacions de l'Abadia de Montserrat.

Segura, C. (2001) Variació dialectal i estandardització al Baix Vinalopó. Alacant: Universitat d'Alacant (Departament de Filologia Catalana). [Tesi doctoral. Disponible a http://rua.ua.es/dspace/handle/10045/5112 Consulta: 7 de gener de 2013]

Sistac, R. (1993) El ribagorçà a l'Alta Llitera: els parlars de la vall de la Sosa de Peralta. Barcelona: Institut d'Estudis Catalans.

\section{TAULES, GRÀFICS I MAPES}

TAULA I: CONSONANTS LABIALS + /A/ FINAL

\begin{tabular}{|l|l|c|c|}
\hline \multicolumn{1}{|c|}{ PARAULA } & \multicolumn{1}{c|}{ MUNICIPI } & F1 (Hz) & F2 (Hz) \\
\hline cama & Alendo & 640,74955 & 1602,686091 \\
\hline ceba & Altron & 600,117064 & 1168,864178 \\
\hline herba & Anàs & 765,753747 & 1585,190897 \\
\hline mama & Baén & 727,770234 & 1632,394386 \\
\hline herba & Capdella & 574,391216 & 1284,845536 \\
\hline
\end{tabular}




\begin{tabular}{|l|l|l|l|}
\hline \multicolumn{1}{|c|}{ PARAULA } & \multicolumn{1}{c|}{ MUNICIPI } & F1 (Hz) & F2 (Hz) \\
\hline problema & Capdella & 517,768059 & 1550,79232 \\
\hline buníssima & Escós & 604,523729 & 1439,192824 \\
\hline màxima & Espot & 702,18104 & 1337,420769 \\
\hline roba & Gerri & 587,936786 & 1225,045742 \\
\hline herba & Lleret & 667,135852 & 1134,398793 \\
\hline sistema & Mont-ros & 478,903535 & 1091,060587 \\
\hline roba & Montardit de B. & 608,236817 & 1219,795822 \\
\hline poblema & Montcortés & 534,734585 & 1236,81943 \\
\hline rama & Montesclado & 821,582117 & 1316,786457 \\
\hline roba & Peracalç & 561,282294 & 992,419475 \\
\hline roba & Rialp & 623,249941 & 1273,016513 \\
\hline roba & Ribera & 608,335159 & 1263,157059 \\
\hline broma & Soriguera & 668,864717 & 1866,017952 \\
\hline calma & València & 747,705796 & 1480,220437 \\
\hline
\end{tabular}

TAULA 2: CONSONANTS DENTOALVEOLARS + /A/ FINAL

\begin{tabular}{|l|l|c|l|}
\hline \multicolumn{1}{|c|}{ PARAULA } & \multicolumn{1}{c|}{ MUNICIPI } & F1 (Hz) & \multicolumn{1}{c|}{ F2 (Hz) } \\
\hline casa & Alins & 547,325219 & 1337,338539 \\
\hline Lleida & Caregue & 582,563618 & 1699,586182 \\
\hline xarrada & Espot & 632,612591 & 1380,593209 \\
\hline temporada & Gavàs & 632,840917 & 1234,248985 \\
\hline bicicleta & Gerri & 566,992028 & 1199,913386 \\
\hline cosa & Guiró & 464,468732 & 1425,269172 \\
\hline festa & Isil & 631,945346 & 1603,973308 \\
\hline cada & Llessui & 504,959035 & 1535,314425 \\
\hline Fecsa & Mont-ros & 546,075042 & 1226,049245 \\
\hline vida & Montardit de B. & 606,412725 & 1402,39472 \\
\hline
\end{tabular}




\begin{tabular}{|l|l|l|l|}
\hline \multicolumn{1}{|c|}{ PARAULA } & \multicolumn{1}{c|}{ MUNICIPI } & \multicolumn{1}{c|}{ F1 (Hz) } & \multicolumn{1}{c|}{ F2 (Hz) } \\
\hline diferenta & Montcortés & 540,785148 & 1389,121299 \\
\hline xavaleta & Montesclado & 667,448978 & 1368,894683 \\
\hline vuitanta & Norís & 527,698837 & 1435,074251 \\
\hline vida & Romadriu & 546,13371 & 1608,468557 \\
\hline fita & Rubió & 442,279187 & 1409,94349 \\
\hline casa & Soriguera & 584,086906 & 1397,602767 \\
\hline Lleida & Sort & 554,779937 & 1496,142612 \\
\hline casa & Tavascan & 595,426105 & 1426,561448 \\
\hline sota & Tírvia & 658,07727 & 1160,36046 \\
\hline Lleida & València & 597,344832 & 1726,6804 \\
\hline
\end{tabular}

TAUla 3: CONSONANTS PALATALS + /A/ FINAL

\begin{tabular}{|l|l|l|l|}
\hline \multicolumn{1}{|c|}{ PARAULA } & \multicolumn{1}{c|}{ MUNICIPI } & \multicolumn{1}{c|}{ F1 (Hz) } & \multicolumn{1}{c|}{ F2 (Hz) } \\
\hline guella & Alins & 596,122589 & 1407,842143 \\
\hline montanya & Isil & 545,844171 & 1867,755299 \\
\hline pubilla & Llavorsí & 471,317513 & 1550,770766 \\
\hline llenya & Llessui & 545,24411 & 1604,512022 \\
\hline Melilla & Rialp & 447,814352 & 1583,182586 \\
\hline canalla & Ribera & 687,771935 & 1771,455192 \\
\hline ascudella & Soriguera & 568,462659 & 1401,208183 \\
\hline filla & Altron & 636,300217 & 1746,145875 \\
\hline muntanya & Baiasca & 583,150875 & 1483,546928 \\
\hline Catalunya & Escós & 691,972433 & 1705,090646 \\
\hline filla & Espot & 646,837434 & 1674,635426 \\
\hline Unya & Gerri & 581,801135 & 1568,06252 \\
\hline auvella & Mont-ros & 537,294665 & 1661,178303 \\
\hline
\end{tabular}




\begin{tabular}{|l|l|c|l|}
\hline \multicolumn{1}{|c|}{ PARAULA } & \multicolumn{1}{c|}{ MUNICIPI } & \multicolumn{1}{c|}{ F1 (Hz) } & \multicolumn{1}{c|}{ F2 (Hz) } \\
\hline Sevilla & Montardit de B. & 484,906102 & 1568,089882 \\
\hline auvella & Montcortés & 546,394595 & 1581,51331 \\
\hline Tonya & Norís & 670,988095 & 1613,148766 \\
\hline guella & Sort & 552,170118 & 1785,852842 \\
\hline Capdella & La Pobleta & 643,08782 & 1307,305502 \\
\hline montanya & Son & 597,64164 & 1611,758432 \\
\hline montanya & Tavascan & 637,094955 & 1597,504803 \\
\hline
\end{tabular}

TAULA 4: CONSONANTS VELARS + /A/ FINAL

\begin{tabular}{|l|l|c|c|}
\hline \multicolumn{1}{|c|}{ PARAULA } & \multicolumn{1}{|c|}{ MUNICIPI } & F1 (Hz) & F2 (Hz) \\
\hline venga & Llessui & 546,750731 & 1382,166772 \\
\hline venga & Montesclado & 661,766489 & 1545,499943 \\
\hline poca & Romadriu & 600,464993 & 1106,73329 \\
\hline butiga & Sort & 432,968708 & 1585,36358 \\
\hline bunica & Tornafort & 411,396104 & 1337,8304 \\
\hline diga & Caregue & 580,516764 & 1537,814583 \\
\hline blanca & Gerri & 707,728576 & 1513,524932 \\
\hline coca & Roní & 702,151609 & 1213,71659 \\
\hline plega & Son & 404,289072 & 1310,253922 \\
\hline poca & Tavascan & 561,651344 & 1215,758444 \\
\hline pega & Aineto & 640,922965 & 932,146058 \\
\hline blanca & Bretui & 453,27178 & 1448,462836 \\
\hline faiga & Jou & 445,215992 & 1541,399804 \\
\hline fàbrica & Aidí & 573,324875 & 1135,552968 \\
\hline diga & Ainet de B. & 680,581385 & 1490,277578 \\
\hline
\end{tabular}




\begin{tabular}{|l|l|c|c|}
\hline \multicolumn{1}{|c|}{ PARAULA } & \multicolumn{1}{c|}{ MUNICIPI } & F1 (Hz) & F2 (Hz) \\
\hline roca & Bernui & 602,591795 & 1174,164541 \\
\hline venga & Capdella & 588,334631 & 1363,874765 \\
\hline coca & Mont-ros & 573,279804 & 1129,218517 \\
\hline pesca & Roní & 717,760006 & 1554,899947 \\
\hline plega & València & 472,825526 & 1386,879358 \\
\hline
\end{tabular}

TAula 5: CONSONANT LATERAL ALVEOLAR VElaRitzada + /A/

\begin{tabular}{|l|l|l|l|}
\hline \multicolumn{1}{|c|}{ PARAULA } & \multicolumn{1}{c|}{ MUNICIPI } & F1 (Hz) & F2 (Hz) \\
\hline taula & Ainet de C. & 639,564677 & 1267,440619 \\
\hline ascola & Alins & 584,81498 & 1268,526177 \\
\hline mula & Altron & 537,299581 & 1159,881996 \\
\hline Controla-la & Baén & 739,281239 & 1371,89158 \\
\hline Biela & Bonestarre & 718,67928 & 1127,599029 \\
\hline canela & Bretui & 593,181086 & 1528,597649 \\
\hline vela & Escaló & 621,424847 & 1196,085912 \\
\hline sola & Caregue & 558,812788 & 1122,381785 \\
\hline ascola & Isavarre & 612,327309 & 1123,705904 \\
\hline singla & Isil & 636,21288 & 1275,651324 \\
\hline clàusula & la Pobleta & 618,519577 & 1124,894872 \\
\hline mola & Llavorsí & 646,69654 & 1081,240137 \\
\hline escola & Malmercat & 548,726024 & 986,869372 \\
\hline ascola & Mont-ros & 575,151734 & 966,983272 \\
\hline gafa-la & Montcortés & 580,340124 & 1345,252355 \\
\hline arguila & Gerri & 505,154808 & 1386,180744 \\
\hline baixa-la & Montardit de B. & & 1629,346843 \\
\hline
\end{tabular}




\begin{tabular}{|l|l|c|c|}
\hline \multicolumn{1}{|c|}{ PARAULA } & \multicolumn{1}{|c|}{ MUNICIPI } & F1 $(\mathbf{H z})$ & F2 $(\mathbf{H z})$ \\
\hline mola & Soriguera & 602,786991 & 1104,861196 \\
\hline tranquil·la & Tavascan & 743,759624 & 1592,260848 \\
\hline formar-la & València & 819,278102 & 1398,925409 \\
\hline
\end{tabular}

Taula 6: FreqüÈncies Segons Alamon i Recasens.

\begin{tabular}{|c|c|c|}
\hline VOCALS & F1 (Hz) & F2 (Hz) \\
\hline $\mathbf{i}$ & 334 & 2215 \\
\hline $\mathbf{e}$ & 437 & 1780 \\
\hline $\mathbf{a}$ & 558 & 1724 \\
\hline$\supset$ & 649 & 1526 \\
\hline $\mathbf{0}$ & 606 & 1087 \\
\hline $\mathbf{u}$ & 508 & 1030 \\
\hline$\partial$ & 392 & 1376 \\
\hline
\end{tabular}




\section{FIGURES}

\section{Peus:}

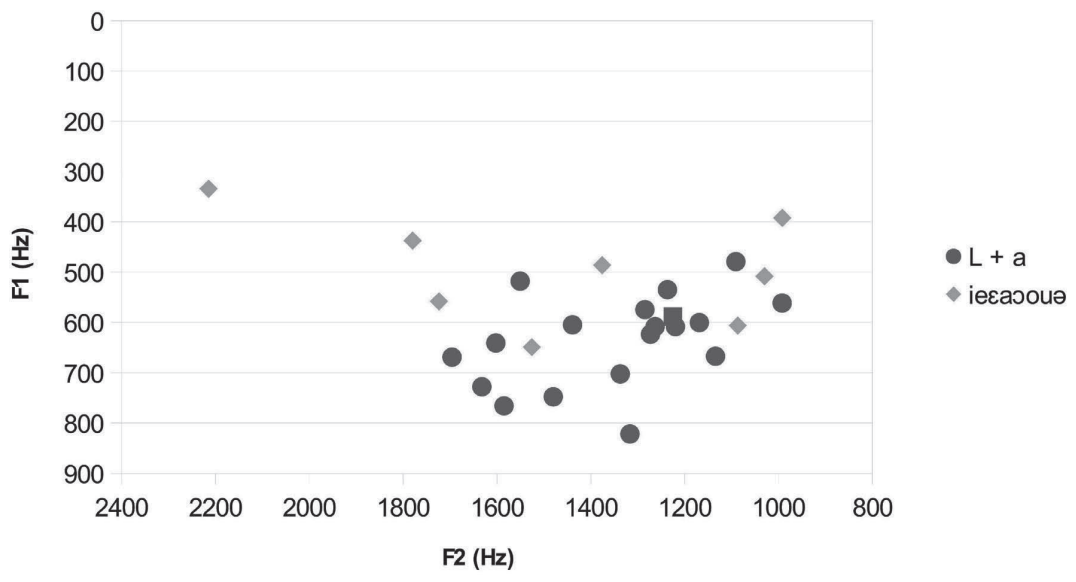

GràFic I: CONSONANTS LABIALS + /A/ FINAL

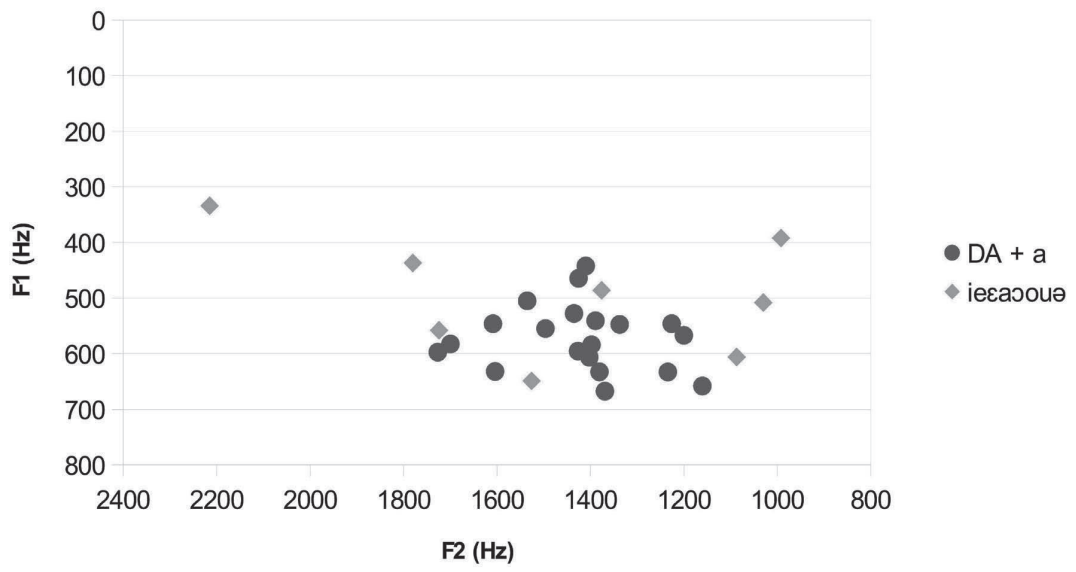

GRÀFIC 2: CONSONANTS DENTOALVEOLARS + /A/ FINAL 


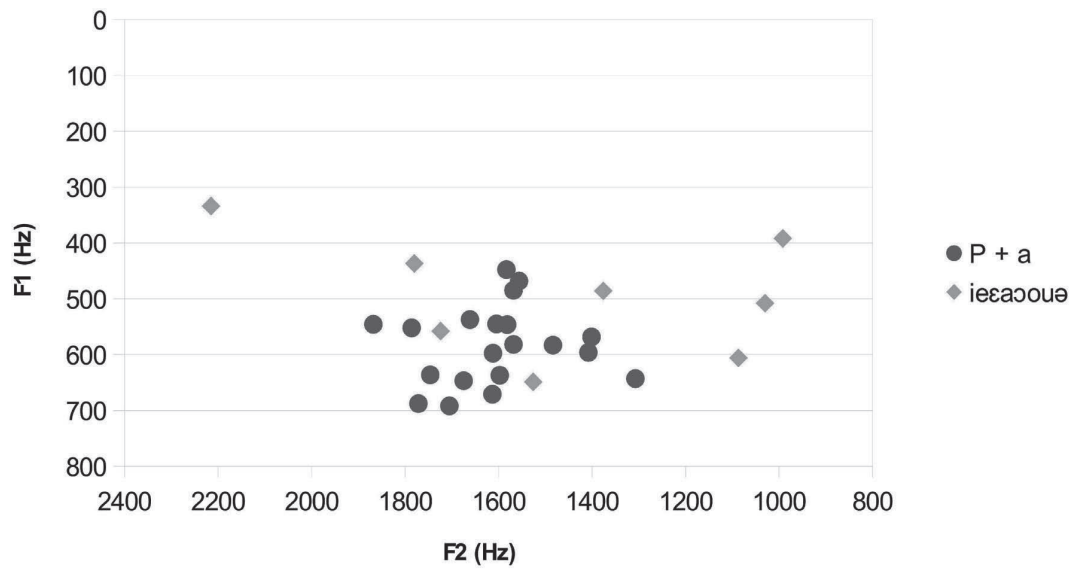

GràFic 3: CONSONANTS PALATALS + /A/ FINAL

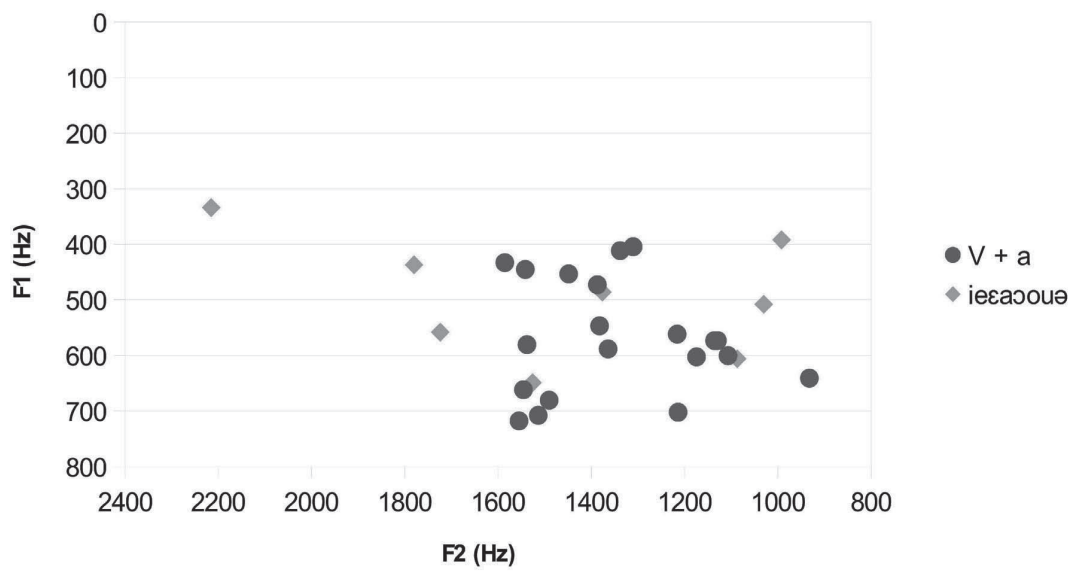

GrÀFIC 4: CONSONANTS velars + /A/ FINAL 


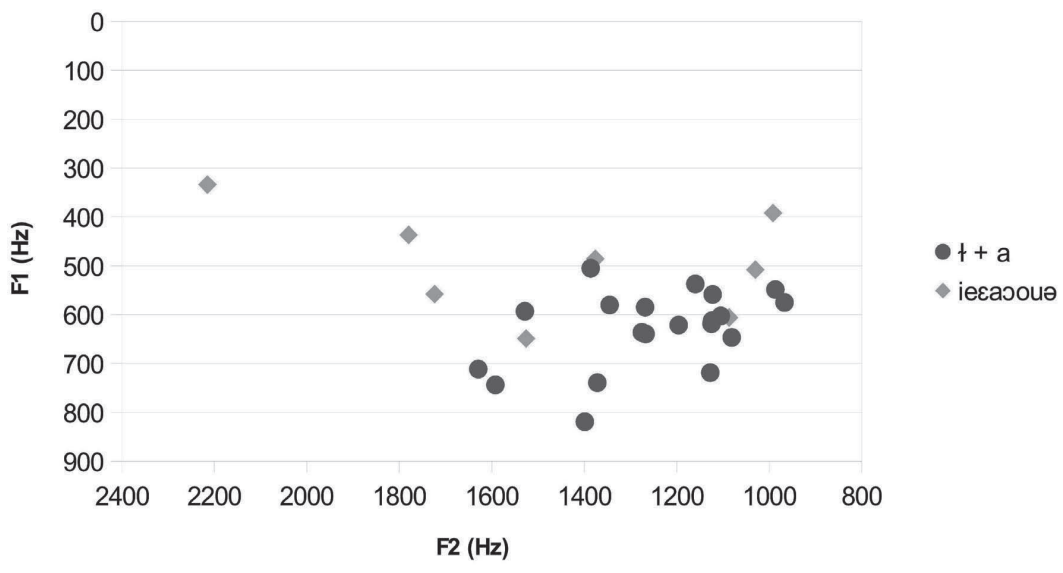

GRÀFIC 5: CONSONANT LATERAL ALVEOLAR VELARITZADA + /A/ FINAL

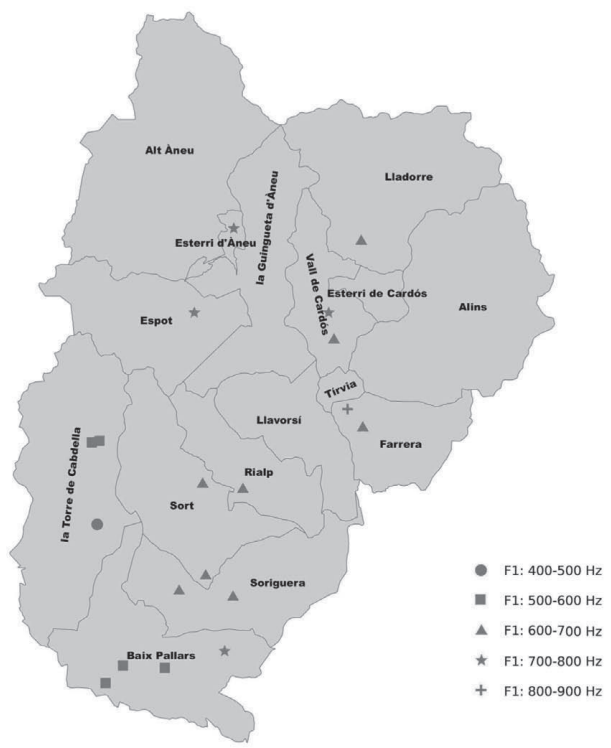

Mapa i: Fi CONTACTE CONSONANTS Labials 


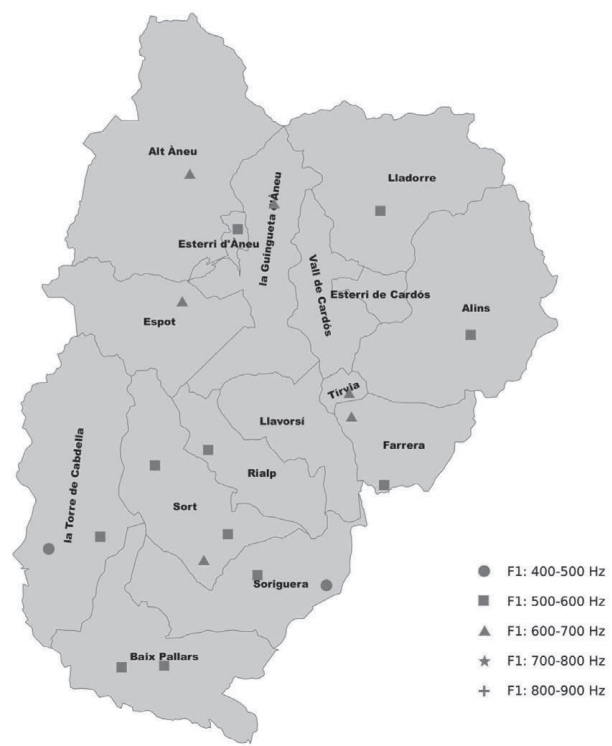

MAPA 2: Fi CONTACTE CONSONANTS DENTOALVEOLARS

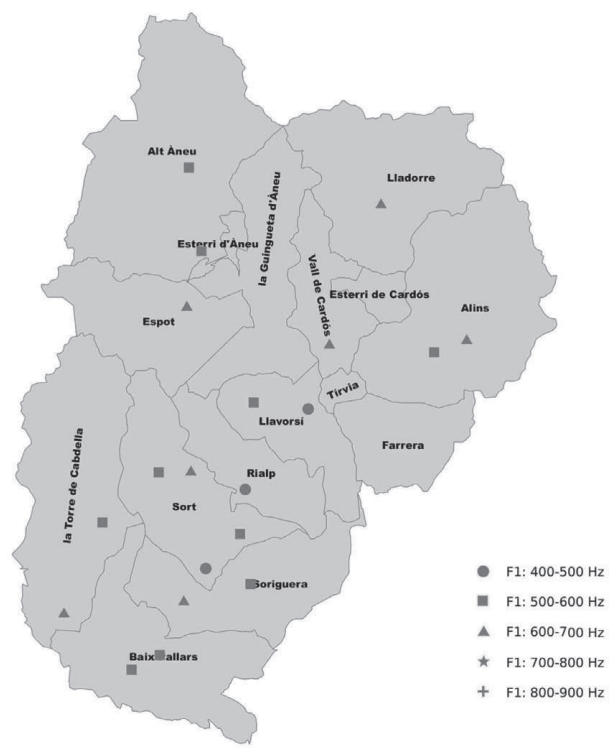

Mapa 3: Fi contacte CONSONANTS Palatals 


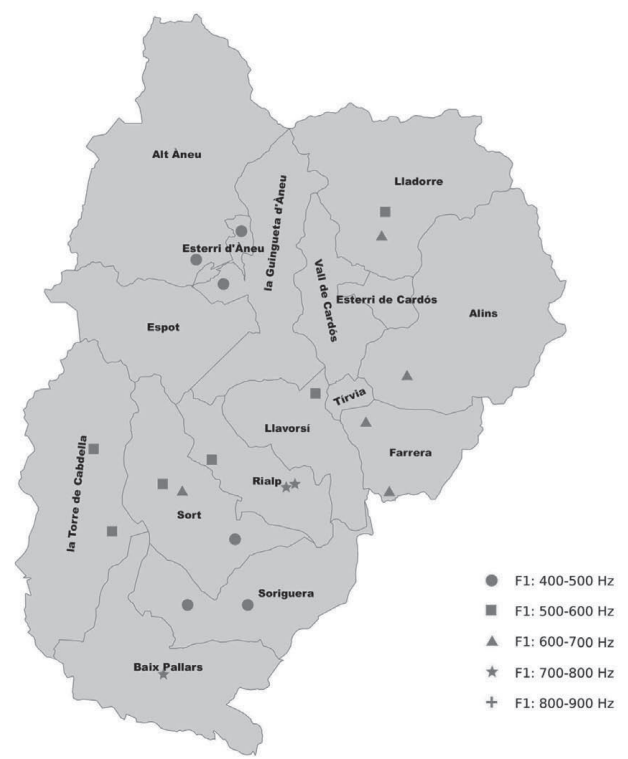

MAPA 4: Fi CONTACTE CONSONANTS VELARS

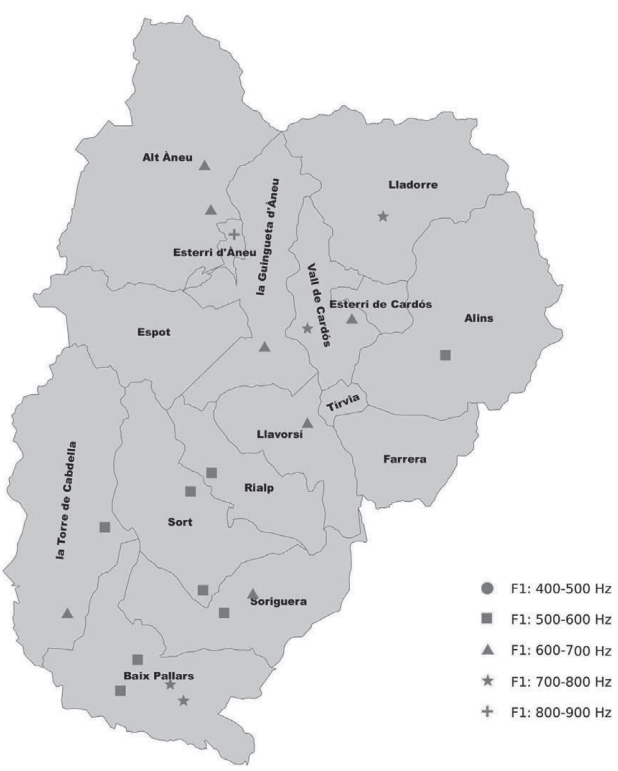

MAPA 5: Fi CONTACTE CONSONANT LATERAL ALVEOLAR VElaRitZadA 


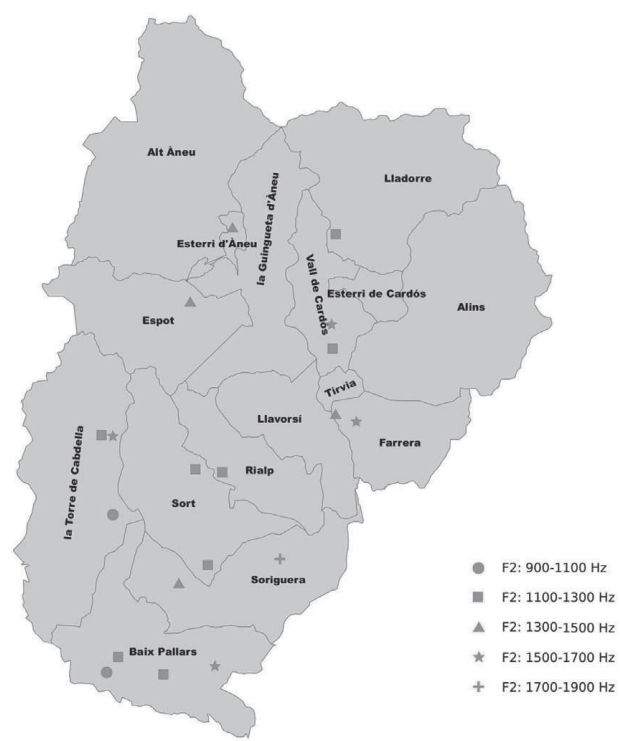

Mapa 6: F2 CONTACTE CONSONANTS Labials

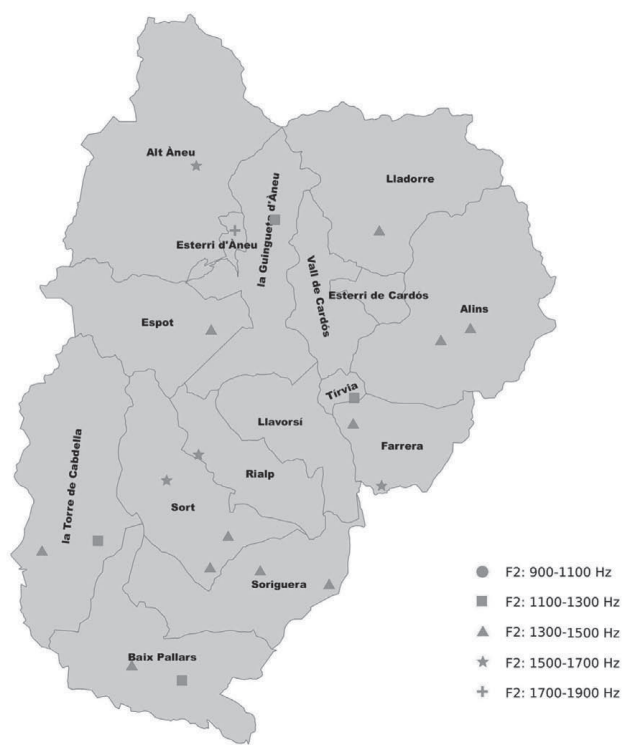

MAPA 7: F2 CONTACTE CONSONANTS DENTOALVEOLARS 


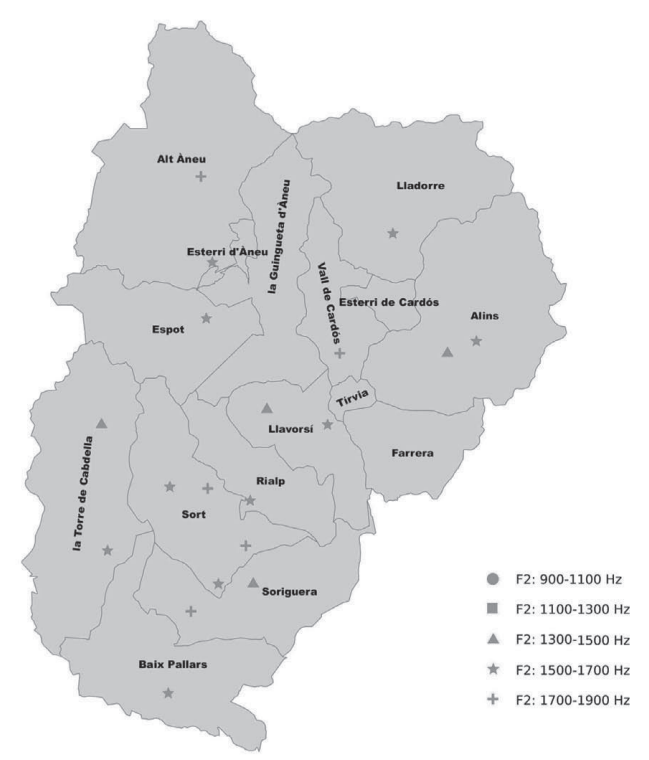

MAPA 8: F2 CONTACTE CONSONANTS PALATALS

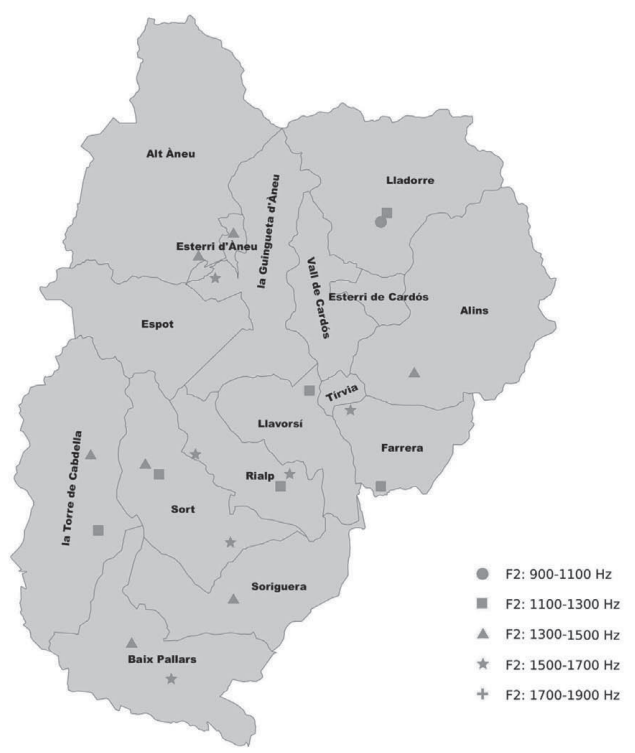

MAPA 9: F2 CONTACTE CONSONANTS VELARS 


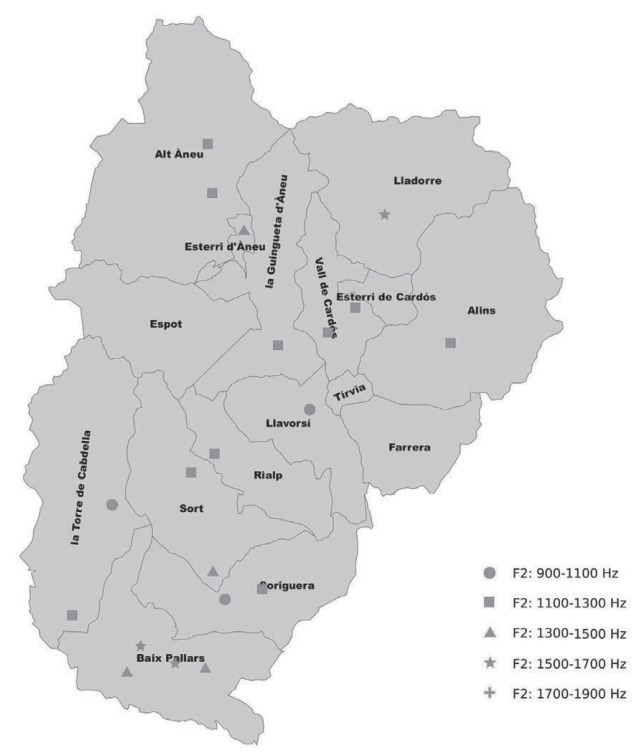

MAPA IO: F2 CONTACTE CONSONANT LATERAL ALVEOLAR VELARITZADA 
